\title{
Research on the Corporate Strategy's Influence on Enterprise Development
}

\author{
Maike Zhou \\ School of Mechanical Engineering, Shanghai Institute of Technology, Shanghai201418, China \\ zmk430@126.com
}

\begin{abstract}
Corporate strategy is a strategic goal that a company develops in the face of a large and complex market situation and in accordance with its external business conditions, which determines the company's overall development in a long time. It's a guide to the business operations' direction and the backbone of the entire enterprise development. Firstly, this paper introduces the definition and classification of corporate strategy; Secondly, we summarize the current research status of the corporate strategy's influence on enterprise development; Then, JD Company is used as a case study to explore the impact of its corporate strategy on its development; Lastly, this paper summarize the specific impact indicators of corporate strategy on enterprise's development and gives the fivedimensional principle of enterprise development strategy.
\end{abstract}

Keywords: Corporate Strategy, Enterprise Development, Impact Indicators, Five-Dimensional Principle.

\section{Introduction}

"Strategy" begins at the military field, which mainly refers to the overall layout and planning of military war. Since then, the term "strategy" has been widely used in political, business, economic and social fields, after combining with modern enterprise management, the concept of "Enterprise Strategic Management" has produced. Professor Gerry Johnson and Kevan Scholes, the two strategic managers in UK, believe that the corporate strategy is the owner's expectation to match the resources, consumers or customers in the changing environment under ideal conditions.

Corporate strategy can be divided into three levels: company strategy, business strategy and functional strategy. The so-called company strategy is also called overall strategy, which is based on the enterprise's goal to reasonably allocate the resources required for the business operation in the field where the enterprise has a competitive advantage. Business strategy aims at concertizing the corporate objectives, development directions and measures to form a specific competition and business strategy for its business unit. The strategy of how to better serve the various levels of professional work (such as marketing, production, finance, etc.) in the enterprise to improve organizational efficiency is the functional strategy.

\section{Literature Review}

GE Liang (2016) thought that the choice of technology development strategic has great significance and profound impact to the survival and development of the enterprise, so he studied the impact of technology life cycle on enterprise technology development strategy using Samsung as an example, aiming at providing some advice of technical development strategy for Samsung.

Pan Yao (2018) selected KONE ELEVATOR Company as an example to analysis how can enterprises effectively and rationally use their own resources and capabilities to establish and develop core competitiveness, formulate strategic goals, and implement strategic decisions to achieve sustainable development based on the existing strategic management theory. Sun Chen (2017) did an in-depth analysis of how the external environment affect enterprises' development, aiming at providing a reference for better enhancing the competitiveness of enterprises. Liu shenao \& Shi zhanzhong (2017) built the Cobb-Douglas production function based on the strategic emerging industry composite index, they measured the distortion of factor prices from 2007 to 2016 in order to explore how factor price distortion impact business' development. Feng guangshun (2018) thought that the enterprises' development penetrated into human resource management, which can enhance 
the core competitiveness effectively, so he did a research on how human resource configuration impact the enterprises' development strategy, whose purpose is to give advice from the perspective of human resources.

\section{JD Corporate Strategy on Its Development}

\subsection{Introduction of JD}

In 2004, JD officially entered the field of e-commerce. JD is officially listed on the NASDAQ Stock Exchange on May 2014, which is the first Chinese large-scale integrated e-commerce platform that successfully went public in the US. In July 2015, JD was selected for the Nasdaq 100 Index with its high growth. In July 2017, JD secondly entered the (Fortune) Global 500, whose market transaction volume was close to 1.3 trillion yuan; and in July 2018, JD thirdly entered the (Fortune) Global 500, ranking thirdly in the world after Amazon and Alphabet.

Great enterprises need firm belief and strong foundation, so it has 14 rules to help employees improve their productivity, they are rules of Value first, ABC, one belt two, Backup, No No No, seven up and eight times, nine palaces eliminated, Two rounds, 8150, 24Times, Three meetings, Assessment of iron man, Internal communication, Five open Organization. All these rules help JD stuff to work more effectively, which laid a solid foundation for the faster and better development of JD.

\subsection{Corporate Strategy Development}

JD changed its name from JD Mall to JD, and established JD Finance and JD Logistics. in recent years, its strategy has become more and more focused, forming an "inverted triangle strategy." The front end is the user experience, the back end is the cost and efficiency. JD gradually made clear that it should only do three business--e-commerce, finance, logistics (including cloud computing), and did not allow anyone to discuss other businesses. JD current strategic organizational structure is as follows:

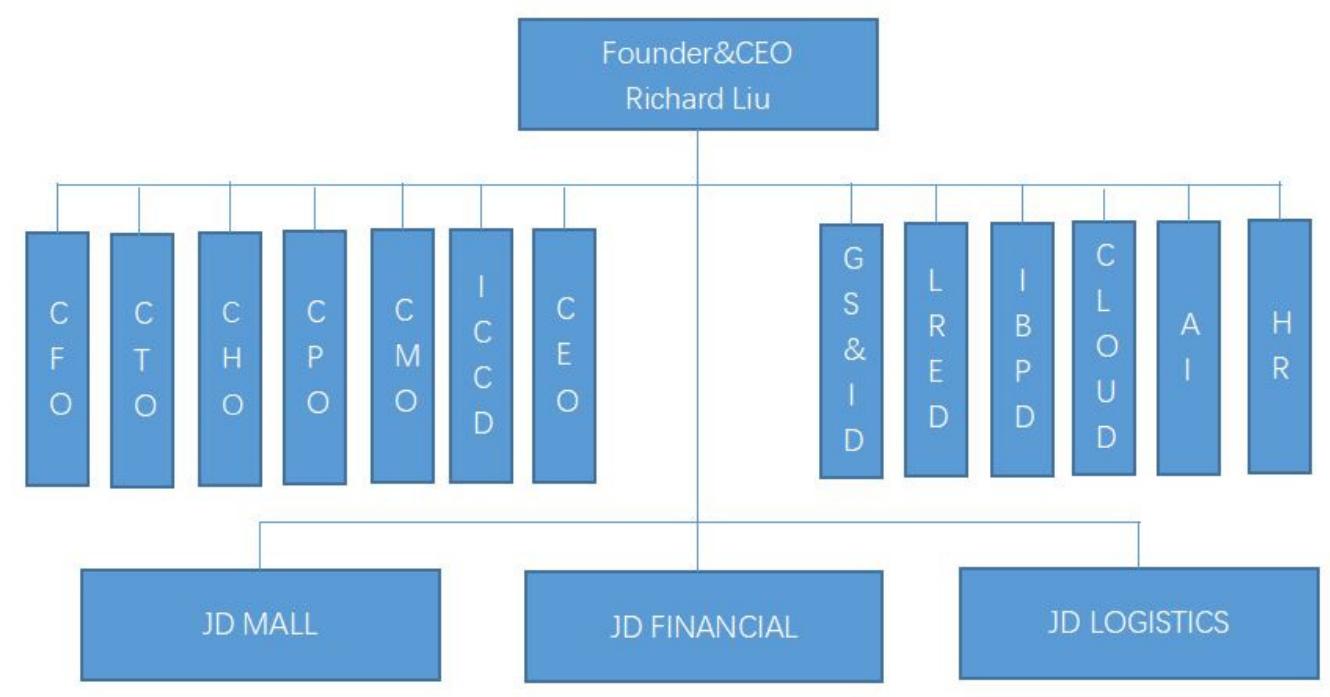

Figure 1. JD current strategic organizational structure

JD strategy transformation is mainly reflected in the company strategy (from a pure e-commerce strategy to a comprehensive e-commerce to a social e-commerce) and business strategy (from a single mall strategy to a mall, finance and logistics). The major events of its strategic transformation and development are as follows: 


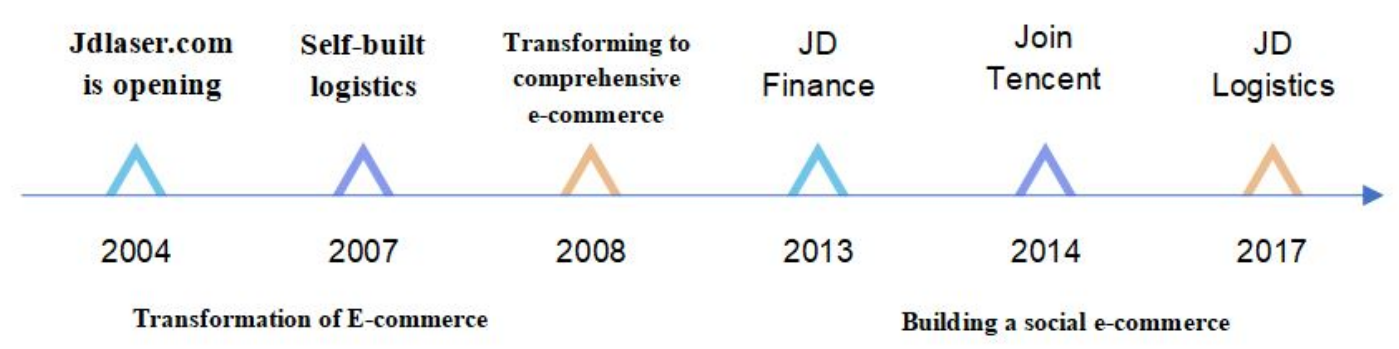

Figure 2. The major events of JD strategic transformation and development

In 2018, JD strategy focuses on cloud computing and unbounded retail. In the transformation of technology, JD has formed a distinct ABC technology development strategy. In the field of artificial intelligence (AI), JD launched the open artificial intelligence platform NeuHub with accurate data accumulation and rich application scenarios; in the field of Big Data, it has long industry value chain big data resources and excellent data quality, and established the first national drone public welfare rescue team. In the field of Cloud Computing, it will provide RaaS (Retail-as-a-Service) solutions as a retail infrastructure service provider, and independently developed the first cloud computing machine JD System 360.

In terms of unbounded retail, from 2017 onwards, JD has developed its industrial layout with the concept of openness, symbiosis, mutual benefit and regeneration in the unbounded retail landscape of "unlimited scenes, boundless goods, people and enterprises", aiming at actively promoting to "retail + retail infrastructure service providers" strategic transformation and redefining cost, efficiency, and experience on the basis of "knowing people," "knowing the field," and "knowing goods". In 2018, JD teamed up with Google, QIY, MUJI, QM, etc. to open online and offline services, and invited international brands MARY KATRANTZOU, CARANDACHE, BALENCIAGA, BOSS, JUDITH LEIBER to continue to stay in the world.

\subsection{The Influence of JD Enterprise Strategy on Its Development}

JD strategic adjustment of its enterprises at different stages is the adaptation to the industry's environment and market development trends. The adjustment of these strategies also enables JD to develop steadily. The transaction volume during the year increased by 130,000 times. JD average annual compound growth rate is close to $150 \%$, and its service covers more than 1 billion users in China. The financial report for Q2 in 2018 shows that its net income has reached a new high of 122.3 billion yuan, a year-on-year increase of 51\%. Among them, logistics and other services revenue increased by $151 \%$ year-on-year, JD Mall's operating profit margin reached $1.1 \%$, a significant increase from $0.8 \%$ in the same period of last year. By the end of June 30, 2018, the number of active users in the past 12 months reached 313.8 million.

\section{The Impact of Corporate Strategy on Enterprise Development}

\subsection{Impact Indicators of Corporate Strategy on Enterprise Development}

The corporate strategy determines the direction and goals of the company's development, which is related to the fate of the company's life and death. What to do is more important than how to do it. Therefore, a good corporate strategy is the decisive factor that determines the development of a company in the right direction. The dimensions of corporate strategy's impact on Enterprise Development are shown in the following figure: 


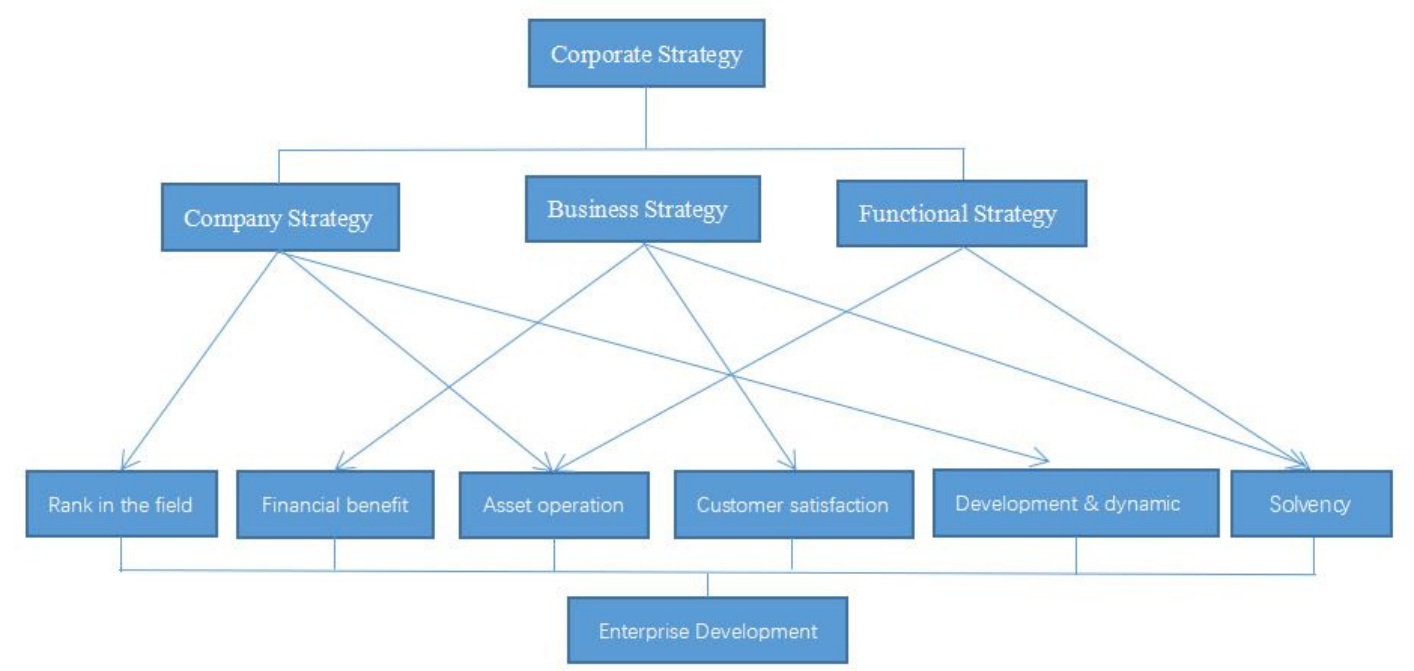

Figure 3. the dimensions of corporate strategy's impact on Enterprise Development

\subsection{Five-Dimensional Principles for Enterprises to Develop Strategies}

Corporate strategy is a general term for various enterprises' strategies, including competitive strategies, marketing strategies, development strategies, brand strategies, financing strategies, technology development strategies, talent development strategies, resource development strategies, etc. Although there are many kinds of corporate strategies, the basic attributes are the same, they are all strategies for the overall, long-term and basic problems of enterprises. Therefore, the formulation of corporate strategy must rely on the comprehensive environment of the industry and the comprehensive consideration of its own resources. The general enterprise should consider the following dimensions when formulating strategies:

\subsubsection{Dimension 1: Thinking Strategy}

To create a sustainable competitive advantage, enterprises must establish a correct strategic. Thinking strategy is the core factor of enterprises' competition. To become a first-class enterprise, we must have a first-class thinking strategy. Firstly, enterprises must carry out strategic analysis, and adhere to the strategic view of both internal and external considerations; Secondly, companies need to make strategic development choices. Enterprises need to decide whether to leave the original industry or enter the new industry; Lastly, enterprises need to establish a strategic direction to win the competition, which means to cultivate the strategic competitiveness of enterprises and integrate corresponding industrial resources to win consumers' choice and loyalty.

\subsubsection{Dimension 2: Business Strategy}

All companies are constantly facing the improvement of customer expectations and the increasingly fierce competition. Company needs to carry on their business strategy to optimize the business structure and allocate resources reasonably. Enterprises need to understand and adapt to the changing characteristics of customer needs, correctly understand the trend of business model transformation, and formulate market/product/manufacturing/sales/service/ strategies according to customer needs.

\subsubsection{Dimension 3: Operational Strategy}

All strategies will eventually return to the actual operation of enterprises. So scientific and organic operation management is a necessary condition for long-term stable development and competitive advantage. The idea of operation management is to continuously improve the operation and technology of business, and adopt advanced management ideas and methods of today's business world. Companies can develop operational strategies in terms of quality, delivery speed, cost, resilience to demand changes, flexibility and speed of new product development, and support products or services related to specific products. 


\subsubsection{Dimension 4: Informational Strategy}

In the process of money from goods to value-added money, capital turnover is generally less than $20 \%$ for manufacturing, and $80 \%$ of time is concentrated in procurement, transportation, sales, inventory and other processes. Therefore, enterprises need to carry out information reform to use emerging technologies such as cloud computing, big data, artificial intelligence, and Blockchain to help enterprises integrate data in procurement, manufacturing, transportation, sales, and inventory to effectively integrate resources. Aiming at accelerating capital turnover and generating many new capital resources. The competition of enterprises is not the competition of individual enterprises, but the competition of the entire supply chain of enterprises, so the timely informational strategy will help enterprise to integrate all internal and external effective resources.

\subsubsection{Dimension 5: Transform and Cultural Strategy}

In the case that management tools and ideas are in urgent need of innovation, it is necessary to improve the organizational structure of the enterprise and the internal control system. Transform strategy is based on the study of organization's positioning, structure, rules of internal operations, rights and benefits distribution systems, business processes and so on. Organizational change is a long-term dynamic process, correct change will bring about earth-shaking changes to the enterprise, stimulating the company to enter a higher stage. At the same time, culture is the source of corporate competitiveness. That is to say, corporate culture is a supplement to the corporate management system, which is like an informal system encouraging and constraining employees through self-discipline and a sense of mission.

\section{References}

[1]. Ge Liang. Technology Life Cycle Impact on Enterprise Technology Development Strategy: Taking Method for Manufacturing Graphene of Samsung As an Example [D]. Nanjing University of Technology.

[2]. Pan Yao. The impact of strategic management on corporate sustainability [J]. Management, 2018.05. DOI: 10.14013/j.cnki.scxdh.2018.05.061.

[3]. Sun Chen. Talking about the Influence of External Environment on Enterprise Development Strategy [J]. Operators, 2017.09: 1672-2507.

[4]. Liu shenao, Shi zhanzhong. Factor Price Distortion and Its Impact on Enterprise Development [J]. Industrial Economics, 2017.04: 11-14.

[5]. Feng guangshun. The impact of human resource allocation on corporate development strategy [J]. Global market: business management, 2018 (21). 